\title{
México y Japón después de la declaración del estado de guerra a las potencias del Eje
}

DOI: $10.32870 /$ mycp.v2i5.410

Carlos Uscanga ${ }^{1}$

\section{Resumen}

Después del ataque japonés a la bahía de Pearl Harbor el 7 de diciembre de 1941, México tuvo que enfrentar una de sus más complejas decisiones de política exterior. Japón se convertía ahora en enemigo. En mayo de 1942 la administración de Manuel Ávila Camacho declaró el "estado de guerra" a las potencias del Eje como resultado del hundimiento de los buques Potrero del Llano y Faja de Oro.

En ese contexto, el Gobierno mexicano implementó diversas políticas para la confiscación de los recursos financieros y propiedades de los ciudadanos de los "países enemigos". Esas acciones originaron una batalla interna entre políticos, funcionarios y empresarios que habían tenido contactos cercanos con los intereses japoneses en México, donde las presiones políticas y el tráfico de influencias fue una constante. Lo anterior se ejemplifica de manera clara en el caso de la mina "La Azul", ubicada en Taxco, Guerrero.

Palabras clave: Segunda Guerra Mundial, rompimiento de relaciones diplomáticas, declaración del estado de guerra, confiscación, potencias del Eje.

Artículo recibido el 12 de febrero de 2013 y dictaminado el 04 de abril de 2013.

1. Profesor-investigador del Centro de Relaciones Internacionales de la Facultad de Ciencias Políticas de la UNAM. Doctor en Cooperación Internacional por la Universidad de Nagoya, Japón. Correo electrónico: uscangap@yahoo.com 


\section{Abstract}

After the Japanese attack on Pearl Harbor Bay on december 7, 1941, Mexico had to face one of its most complex foreign policy decisions. Japan now became enemy. In may 1942, the administration of Manuel Avila Camacho declared a "state of war" to the Axis powers as a result of the sinking of ships Potrero del Llano and Faja de Oro.

In this context, the Mexican government implemented various policies for the confiscation of financial funds and property of the citizens of "enemy countries". These actions led to a battle over which politicians, officials and businessmen who had close contacts with Japanese interests in Mexico, where political pressures and influence trafficking was a constant. This clearly exemplified in the case of the mine "La Azul", located in Taxco, Guerrero.

Keywords: World War II, breaking of diplomatic relations, declaration of a state of war, confiscation, Axis powers.

\section{Introducción ${ }^{2}$}

Es un hecho que el ataque a Pearl Harbor por parte de los escuadrones japoneses el 7 de diciembre de 1941, tomó por sorpresa a la mayoría de los países del mundo. Si bien las fricciones entre Tokio y Washington habían estado escalando en intensidad y el escenario de enfrentamiento no se visualizaba muy lejano, la incursión al territorio estadounidense y la inhabilitación temporal de su flota naval hizo que muchos países pusieran su atención en los asuntos bélicos, al abrirse ahora el frente de guerra en el Pacífico.

México no fue la excepción. En uno de los periodos más críticos en su política exterior tenía que enfrentar una difícil decisión en momentos por demás complejos, donde los espacios de titubeos o dudas no tenían lugar frente a un proceso que requería una inmediata acción en la toma de decisiones de la administración de Manuel Ávila Camacho (1 de diciembre de 1940-1946), que tenía poco más de un año de haber entrado en funciones. Para México de pronto se convertía Japón en enemigo y tendría que establecer las accio-

2. El presente documento representa los avances de investigación de una exploración histórica de las relaciones económicas y diplomáticas entre México y Japón, en el marco del proyecto SEP-Conacyt de Ciencia Básica 150933: "Acuerdo para el fortalecimiento de la asociación económica MéxicoJapón: Análisis global y sectorial de los flujos comerciales, inversión y cooperación”. 
nes pertinentes para apoyar a Estados Unidos en su cruzada contra ese país asiático que se había alineado con las potencias del Eje a través del Tratado Tripartito del 27 de septiembre de $1940 .^{3}$

Es interesante que durante el periodo comprendido entre el 8 diciembre de 1941 al 22 de mayo de 1942, se observan diferentes planos del comportamiento internacional de México frente a la expansión en el Pacífico de la Segunda Guerra Mundial, antaño concentrada fundamentalmente en el teatro europeo. En primer lugar, se observó el apoyo inmediato a Washington por el ataque japonés; en segundo, el despliegue de la diplomacia multilateral a través de los acuerdos panamericanos; y por último, la resistencia de México para lanzar una declaración de guerra directa contra Japón, limitándose al rompimiento de los nexos político-diplomáticos, a diferencia de otros países de Centro y Sudamérica, que lo habían hecho de manera inmediata.

En el presente artículo se buscan explorar - a través de una aproximación analítico-descriptiva por medio de la revisión de medios impresos y documentos históricos de la época- tres planos de aproximación al tema. En el primero se explica la posición del Gobierno mexicano frente a la apertura de la guerra en el Pacífico y el proceso que derivó en el rompimiento de las relaciones diplomáticas contra Japón y los demás países del Eje. En el segundo se abordan las formas en que México trató de resistir - hasta donde le fue posible- la emisión de una declaración de guerra directa. No obstante, las circunstancias que derivaron en el bombardeo de los buques con bandera mexicana Potrero del Llano y Faja de Oro, obligaría al gobierno avilacamachista a asumir una posición - misma que de manera hábil y de acuerdo con el derecho internacional- justificó con el anuncio del "estado de guerra" contra Japón y sus aliados.

Por último, se realiza un estudio de los problemas derivados de la confiscación de los bienes de los ciudadanos de las potencias del Eje en México; se ilustrará el caso de la Mina Azul, donde diversos intereses estuvieron en juego involucrando a importantes personajes de influencia en la esfera política mexicana, como el general Juan Barragán Rodríguez y el doctor Kiso Tsuru, dueño de diversas empresas —entre ellas la Turu o Tsuru Mining Co-, siendo ellos algunos de los actores principales de una serie de reclamaciones - que incluso se elevaron a demandas judiciales-. Diversos esfuerzos se realizaron

3. El pacto fue firmado por Adolfo Hitler, Galeazzo Ciano, ministro del Exterior de Italia, y Saburo Kusuru, embajador japonés en Alemania. 
por parte de los políticos y empresarios mexicanos antaño asociados a los intereses japoneses en México, para obtener el control de las mismas. Más allá de la limitada participación mexicana en las contiendas bélicas en la Segunda Guerra Mundial, quizá el problema de la administración de los bienes de las "naciones enemigas" representó un tema álgido en el escenario político mexicano después de la declaración del estado de guerra.

\section{Japón: de amigo a enemigo}

Pearl Harbor indudablemente cambió la imagen de Japón en la opinión pública mexicana. Con diversas tonalidades surgieron opiniones sobre la necesidad de que México asumiera sus compromisos internacionales para garantizar la seguridad de los países del hemisferio occidental frente a la amenaza inflingida a Estados Unidos.

Los márgenes de maniobra para refrendar la neutralidad ante el conflicto europeo, heredada del gobierno de Lázaro Cárdenas, se colapsaron. Ezequiel Padilla, secretario de Relaciones Exteriores, anunciaba de manera oficial la ruptura de los nexos diplomáticos entre México y Japón. En un mensaje a la prensa escrita lo refería así:

\footnotetext{
El Gobierno de México, que ha preconizado invariablemente el respeto absoluto de los compromisos internacionales voluntariamente contraídos no puede dejar de estimar como natural consecuencia de la declaración citada, que el mantenimiento de sus relaciones diplomáticas con el Japón resultan incompatibles con el acto de agresión que cometió éste en contra de Estados Unidos de América [...] En tal virtud se ha impartido instrucciones a nuestro ministro en Tokio para que, previa notificación de lo que procede a las autoridades ante las cuales se halla acreditado, proceda a clausurar la Legación y el Consulado en Yokohama. La anterior decisión ha sido comunicada al ministro del Japón en esta capital para los efectos similares; habiéndose cancelado, a partir de esta fecha, la autorización provisional concedida a los agentes consulares de dicho Imperio en la República Mexicana (El Universal, 1942a: 1).
}

La maquinaria gubernamental se movilizaba frente a los momentos críticos que demandaba la toma de decisiones en un escenario de crisis. México refrendaba la necesidad del rompimiento de sus nexos diplomáticos evitando el anuncio de un involucramiento del país en el nuevo frente de batalla que se abría en el Pacífico. En la alocución realizada por el presidente Manuel 
México y Japón después de la declaración del estado de guerra a las potencias del Eje

Ávila Camacho desde Palacio Nacional — transmitida en cadena nacional— sobre la posición de México frente al conflicto entre Estados Unidos y Japón, apuntaba que:

Los Estados Unidos de América han sido agredidos por el Japón. Un estado de guerra, oficialmente declarado por las dos partes, existe desde ayer entre ambas naciones. De acuerdo con el espíritu de la declaración emitida por los Estados americanos en la segunda reunión de consulta de los ministros de Relaciones Exteriores, celebrada en La Habana en 1940, México ha roto sus relaciones diplomáticas y consulares con el Imperio japonés. Varias otras repúblicas del hemisferio han precisado su actitud internacional, ya sea merced a declaraciones de guerra, ya por medio de determinaciones de solidaridad semejantes a las que ha tomado nuestro país. En todo el Continente se advierte un igual fervor de solidaridad por causa de los Estados Unidos que, en estos momentos solamente es la causa de América [...] (El Universal, 1941b: 1).

Frente a la exigencia de una mayor alerta y de estar preparado ante una posible incursión externa en el territorio nacional o continental por parte de Japón, se podían identificar posiciones de mayor mesura donde se reconocía la grave situación y la difícil posición del presidente mexicano para evitar caer en tentaciones de involucrar a México de manera directa en el conflicto y convertirlo en un "gambusino de guerra":

La mejor manera como un hombre público puede engrandecerse o empequeñecerse es participando en una crisis. Hemos visto a quienes las fanfarrias de la hora vana proclaman como un superhombre caer ruidosamente cuando el tiempo duro puso a prueba sus dotes de hombre, de director y de encauzador. En cambio, en los más graves trances históricos, hombres a quienes el momento intrascendente tuvo la miopía de negar relieves valiosos, surgieron triunfantes legando prestigios y méritos a la prosperidad. No todos los dirigentes de un país tienen la virtud de saber participar en la Historia [...] Los que fría y calculadamente concibieron la esperanza de ver a México convertido en un gambusino de la guerra, tomando para sí el indigno carácter de especulador preparado para escoger un botín precioso de la contienda, olvidaron que México es un país con vastas reservas morales, con generosa tradición y con sentido de responsabilidad ante sus compromisos históricos. Esta guerra, sepámoslo de una vez, no es una guerra de hombres, ni de apetitos, ni de negociantes. Esta guerra, es una guerra de posiciones morales, en la que luchan dos modos de concebir la vida, con la libertad, y sin la libertad (Flores, 1941: 3). 
El 11 de diciembre México rompió relaciones diplomáticas con Italia y Alemania; la notificación fue entregada por el secretario Ezequiel Padilla y a la salida de los representantes diplomáticos de esos países, el conde Alberto Marchetti y el ministro H. Dudt Von Collenberg, de las oficinas de la Cancillería mexicana, al solicitarles una declaración para los medios, el representante italiano ignoró las peticiones de la prensa, mientras el alemán, de manera irónica, apuntó que sólo podía decir: "Me he quedado sin empleo" (El Universal, 1941c: 1).

El comentario irónico del diplomático alemán se enmarcaba en un clima interno donde diversas opiniones sobre la apertura de la guerra en el Pacífico pudieron ser escuchadas en las esferas políticas y en los medios de comunicación de la época. El Gobierno mantuvo la posición de alianza con Estados Unidos, el apego a los compromisos panamericanos para la defensa mutua y evitando escalar a otro nivel más allá del diplomático, que hubiera significado una declaración abierta de guerra contra Japón y las potencias del Eje.

En este sentido, México renunciaba a cualquier actitud que pudiera interpretarse como agresiva, manteniendo una posición de defensa de su soberanía en concordancia con sus compromisos con su vecino del norte y los contraídos con los otros países latinoamericanos. De tal manera, la suspensión de los nexos diplomáticos estaba en concordancia con sus principios internacionales y con una actitud más de cautela donde, si bien refrendaba la alianza con Estados Unidos, no se involucraba, de primera instancia, en una empresa azarosa.

En el plano continental, la diplomacia mexicana fue muy activa para refrendar esos principios en la tercera reunión de consulta de los ministros de Relaciones Exteriores en Río de Janeiro, Brasil, del 15 al 28 de enero de 1942. México presentó varias iniciativas sobre el rompimiento de los nexos económicos con los países del Eje, el aprovisionamiento de recursos estratégicos y promovió la expresión de solidaridad a los países y territorios ocupados por las naciones "totalitarias" (El Universal, 1941d: 6).

La Conferencia de Río acordó diversos instrumentos interamericanos de consultas y coordinación entre los miembros sobre temas de defensa y asuntos judiciales. A nivel formal, se conformaba un frente ante cualquier posible agresión de los países del Eje, pero el verdadero triunfo fue para Washington, que logró la unidad de América Latina para tener al menos el compromiso de la clase dirigente de cerrar filas frente a los "enemigos". 


\section{La declaración del estado de guerra}

Un nuevo escenario de crisis tuvo que enfrentar el gobierno de Ávila Camacho cuando fue informado por el Consulado mexicano en Miami, Florida, del hundimiento del barco "Potrero del Llano" a casi la media noche del 13 de mayo de 1942, llevando 46 mil barriles de petróleo. El barco había sido incautado a Italia en abril de 1941 por las autoridades mexicanas y tenía 30 años de servicio en el momento del ataque por un supuesto submarino alemán. Las declaraciones del canciller Padilla a la prensa sobre ese suceso fueron las siguientes:

Ningún hecho más grave ha ocurrido para México en el curso de la actual guerra mundial que el hundimiento del barco tanque petrolero con bandera mexicana "Potrero del Llano", por un submarino totalitario [...] Estoy seguro de que este desgraciado suceso hará reflexionar al pueblo mexicano en que el hundimiento de uno de sus barcos, el sacrificio de sus tripulantes, el ultraje a la bandera de México reclaman una actitud de acuerdo con nuestras tradiciones de honor y de defensa de la soberanía nacional. En estos momentos, por instrucciones del señor presidente de la República, la Secretaría de Relaciones a mi cargo ha enviado cablegráficamente a nuestro encargado de negocios en Estocolmo la siguiente declaración que se servirá entregar al ministro de Negocios Extranjeros de Suecia, rogándole transmitirla a las autoridades correspondientes del Tercer Reich, del Reino de Italia y del Imperio del Japón. Si para el próximo jueves 21 del corriente, México no ha recibido del país responsable de la agresión una satisfacción completa, así como las garantías de que le serán debidamente cubiertas las indemnizaciones por los daños y perjuicios sufridos, el Gobierno de la República adoptará inmediatamente las medidas que exija el honor nacional (Excélsior, 1942a: 1).

Las respuestas de las potencias del Eje consistieron en ignorar de manera absoluta la reclamación de México. Alemania se negó incluso a recibir la notificación por parte del representante de la Legación sueca en Berlín, en tanto que en Roma y Tokio no hubo ninguna respuesta. En una breve nota de la Secretaría de Relaciones Exteriores se mencionaba que "[...] será el señor presidente de la República el que resolverá lo que convenga al honor de la Patria" (El Universal, 1942a: 1).

La prensa informaba la nota sobre el hundimiento del buque "Faja de Oro", que había sido bombardeado el 20 de mayo en su viaje de retorno a Tampico después de haber descargado 56 mil barriles de petróleo en el puerto 
de Marcus Hook, Delaware. Se celebró una reunión de emergencia en el salón "Héroes" del Palacio Nacional, donde estuvo el presidente Ávila Camacho acompañado por todos los secretarios de Estado, jefes de Departamentos Autónomos, procurador general de la República, procurador del Distrito y Territorios Federales, el secretario particular y el oficial mayor de la Presidencia, además representantes de los Poderes Legislativo y Judicial a fin de analizar el escenario emergente de crisis y la posición de México frente a ese suceso (El Universal, 1942b: 1).

En sesión solemne frente al Congreso de la Unión, el presidente Manuel Ávila Camacho explicó el 28 de mayo de 1942 el siguiente paso, que involucraba a México militarmente en el conflicto contra las potencias del Eje, dejando atrás las medidas de menor intensidad que había elegido al sólo declarar el rompimiento de las relaciones diplomáticas. Ahora no existía la posibilidad del uso del derecho internacional para sancionar las acciones que se habían cometido contra su soberanía. La decisión pensada e inteligente fue la declaración del estado de guerra:

Dos caminos se ofrecían entonces a México. Uno, el de la guerra. Otro, el de cesación de todas nuestras relaciones con los Estados nazifascistas. Al optar por esta última solución, creímos interpretar adecuadamente el deseo nacional. Debo añadir con satisfacción que nuestra actitud coincidió con la de la mayoría de las repúblicas del Continente y que mereció una aceptación general en la Junta de Cancilleres de Río de Janeiro [...]

Frente a esta reiterada agresión, que vulnera todas las normas del derecho de gentes y que implica un ultraje sangriento para nuestra patria, un pueblo libre y deseoso de mantener sin mancha su ejecutoria cívica no tiene más que un recurso: el de aceptar valientemente las realidades y declarar — según lo propuso el Consejo de Secretarios de Estado y Jefes de Departamentos Autónomos reunidos en esta capital el viernes 22 del corriente- que, a partir de esa fecha, existe un estado de guerra entre nuestro país con Alemania, Italia y Japón. Estas palabras "estado de guerra" han dado lugar a interpretaciones tan imprevistas que es menester precisar detalladamente su alcance. Desde luego, hay que eliminar todo motivo de confusión. El "estado de guerra" es la guerra. Sí, la guerra, con todas sus consecuencias; la guerra, que México hubiera querido proscribir para siempre de los métodos de la convivencia civilizada, pero que, en casos como el presente y en el actual desorden del mundo, constituye el único medio de afirmar nuestro derecho a la independencia y de conservar intacta la dignidad de la República. Ahora bien si el "estado de guerra" es la guerra misma, la razón que 
tenemos para proponer su declaración y no la declaración de guerra, obedece a argumentos muy importantes [...] (Ávila Camacho, 1942: 5-7).

El concepto del "estado de guerra" no estuvo exento de ambigüedades, por lo que fue necesario remarcarlo como lo hizo el presidente en su discurso. El Gobierno tuvo que aclarar que ningún mexicano sería enlistado para irse a la guerra, como se había esparcido el rumor, y las acciones gubernamentales estaban orientadas a agrupar al Ejército y Armada de México para la defensa nacional. Dos días después de su presentación ante el Legislativo, el presidente envió tres iniciativas de ley: la primera sobre la declaración de la existencia del estado de guerra, la segunda sobre la suspensión de las garantías individuales, y la tercera sobre el otorgamiento de facultades extraordinarias al Ejecutivo.

Las expresiones patrióticas fueron la constante en las diferentes opiniones y crónicas aparecidas en la prensa, quizá comparadas con las que habían surgido después de la iniciativa del entonces presidente Lázaro Cárdenas de la expropiación petrolera en marzo de 1938. Ahora el enemigo no amenazaba solamente con las presiones económicas sino con la posibilidad de que México estuviera envuelto en el teatro de hostilidades. El 29 de mayo el Congreso de la Unión aprobó por unanimidad las iniciativas presidenciales, cuyo dictamen final fue:

$1^{\text {a }}$. La declaración de que a partir del día 22 de mayo de 1942 existe un estado de guerra entre los Estados Unidos Mexicanos y Alemania, Italia y Japón. $2^{\mathrm{a}}$. La suspensión de garantías individuales consignadas en los artículos $4^{\circ}$., párrafo primero del $5^{\circ}, 6^{\circ}, 7^{\circ}, 9^{\circ}, 11^{\circ}, 14^{\circ}, 16^{\circ}, 19^{\circ}, 20^{\circ}, 21^{\circ}$, párrafo tercero del $22^{\circ} \mathrm{y}$ $25^{\circ}$ de la Constitución Política de la República. Esta suspensión durará todo el tiempo que México permanezca en estado de guerra con los países del Eje. $3^{\mathrm{a}}$. Autorización al Ejecutivo de la Unión para imponer en los distintos ramos de la Administración Pública todas las modificaciones que fueren indispensables para la eficaz defensa del territorio nacional, de su soberanía y dignidad para el mantenimiento de nuestras instituciones fundamentales; y autorización al mismo Ejecutivo para legislar en los distintos ramos de la propia Administración Pública (Excélsior, 1942b: 1).

La notificación para los países del Eje de la decisión del Congreso de la Unión se dio a través de la entrega por parte de Ezequiel Padilla a los representantes de Suecia, Suiza y Portugal para que fuera remitido el documento a Alemania, Japón e Italia. Asimismo fueron avisados de manera oficial los países aliados 
del continente americano de la decisión de México en la declaración del estado de guerra, donde se hace un recuento de los hechos que orillaron al Gobierno mexicano a esa decisión.

El 3 de junio, un día después de la publicación -en el Diario Oficial de la Federación-de las tres iniciativas presidenciales aprobadas por el Legislativo, el presidente Ávila Camacho de nuevo volvía a dar un mensaje a la nación, donde reiteraba que la decisión de la declaración del estado de guerra contra las potencias del Eje estaba fundada en el interés de la nación y no se había asumido una actitud ligera sino con dignidad, firmeza y clara determinación. México había refrendado su compromiso para reaccionar frente a la agresión de las naciones "enemigas" basado en acendrar el discurso patriótico y la defensa de la soberanía mancillada.

\section{¿Y después de la declaración?}

Más allá del anfiteatro de guerra en el Pacífico y la posterior participación de México en las hostilidades con el envío del Escuadrón 201 de la Fuerza Aérea Mexicana, al interior del Gobierno se libraban otra serie de enfrentamientos en torno al manejo de las concesiones

No puede entenderse la naturaleza de las relaciones políticas y económicas entre México y Japón a lo largo de la década de los treinta y principios de los cuarenta, sin el papel desempeñado por Kiso Tsuru otorgadas a empresas - con participación legal o encubierta- de capital japonés, frente a la congelación de sus bienes y la cancelación de los permisos remanentes para la explotación de petróleo y sobre todo de minerales; en ese último sector los accionistas mexicanos reclamaban el control de las mismas. Algunos de ellos habían sido socios o prestanombres y otros tenían participación como resultado de sus buenos oficios de los intereses japoneses dentro de la élite política mexicana. En esa urdimbre de hechos y reclamaciones, un personaje se erigía como el común denominador: el doctor Kiso Tsuru (Hernández, 2011).

Sin lugar a duda, no puede entenderse la naturaleza de las relaciones políticas y económicas entre México y Japón a lo largo de la década de los treinta y principios de los cuarenta, sin el papel desempeñado por Kiso Tsuru, originario 
de la provincia de Oita, Japón, y naturalizado mexicano desde diciembre de 1935 con folio 1018. Su visión para los negocios bajo una orientación pragmática y su sensibilidad para relacionarse con personajes clave con alta influencia política en ambos países, le permitió concentrar un alto poder financiero que le llevó a operar — casi de manera irrestricta — ganando voluntades, pagando y cobrando favores; así como concentrando información valiosa que la usaría como moneda de cambio para mantener sus prerrogativas e intereses incluso después de finalizar la Segunda Guerra Mundial.

La alta corrupción del Gobierno de México representó el medio ideal para operar - de manera fluida - en la apertura de oportunidades de negocios lucrativos cuya naturaleza se transformó al mismo tiempo en que Japón viraba de una economía de paz, a un modelo orientado al apoyo de las actividades de guerra. En efecto, ese país asiático había logrado incrementar sus capacidades competitivas a través de bajos costos de producción, calidad de sus productos de exportación y la extensión de sus redes de mercadeo a nivel mundial, así como procedimientos innovadores de distribución y de adaptación de sus mercancías a las necesidades de consumo de acuerdo con el poder adquisitivo de cada país. La industria textil fue la punta de lanza del desarrollo, seguida por el fortalecimiento de los bienes de capital y de manufactura, que desafiaban a sus competidores europeos y estadounidenses.

Sin embargo, las acciones proteccionistas y en particular la guerra económica liderada por Estados Unidos contra Japón, marcaron cambios de estrategia ante un escenario de restricción de insumos básicos para su desenvolvimiento industrial y en particular de recursos estratégicos. Ante ese hecho, el Gobierno japonés desplegaría una diplomacia económica para garantizar la obtención de los mismos a través de una agresiva política de diversificación, donde América Latina y México fueron objeto de atención.

La apertura del frente de guerra de Japón en China en el verano de 1937, profundizaría las políticas de embargo estadounidense de recursos e insumos considerados para usos bélicos. La posterior invasión nazi en Polonia a finales del verano de 1939 y la escalada de guerra en Europa, generarían para la economía japonesa un impacto importante. Ante esos eventos, se implementarían acciones de inteligencia donde los vectores económicos y políticos se fusionaban en uno solo tanto para mantener abierta las válvulas de aprovisionamiento de los bienes necesarios destinados a la alimentación del aparato industrial orientado a la guerra, como también para buscar la contención a las políticas de Washington. 
Los instrumentos para el comercio exterior, con su orientación estratégica, implicaron cambios en sus mecanismos de operación. Se implementó un mayor control gubernamental en las importaciones y exportaciones japonesas, se fortalecieron las actividades de las casas comercializadoras (sogo sosha) de las principales zaibatsu, se amplió el papel de sus representaciones diplomáticas para la coordinación de estrategias comerciales y se buscó el uso de miembros influyentes de la comunidad japonesa residente en los diversos países. Ése fue el contexto que incrementó la importancia dentro del ambiente de los negocios en México de Kiso Tsuru.

Si bien a lo largo de 1941, las opiniones expresadas por diplomáticos, funcionarios y empresarios convergían en la inevitabilidad de un posible conflicto armado entre Tokio y Washington, fue un hecho, como ya se apuntó, que el ataque del 7 de diciembre a la bahía de Pearl Harbor representó una sorpresa, no sólo para los tomadores de decisiones sino en particular para el grupo de funcionarios, empresarios y políticos que habían estado ligados a los intereses de Japón en México. En efecto, muchos de ellos fueron facilitadores, por su posición de probada influencia política, cuyo pago de servicios ya sea en monetario, especie o en participación en las acciones de las empresas en el ramo petrolero (La Laguna y la Veracruzana) y minero (Tsuru o Turu Mining Co.) controladas - de manera directa o como intermediario- por Kiso Tsuru. Ese grupo de personas ahora mostraban una actitud diferente.

La posición frente a esa nueva realidad del tránsito de Japón de amigo a enemigo les obligó a definir un posicionamiento. Algunos de ellos optaron, por un lado, por el reconocimiento de su pasado involucramiento en negocios con los japoneses y su posterior deslinde por haber roto relaciones diplomáticas y de estar en un estado de guerra con esa nación asiática. Por otro, el interés de mantener usufructuando su posición como accionistas de las empresas donde ahora reclamaban indemnizaciones o la reintegración de las concesiones por parte de la Junta de Administración y Vigilancia de los Bienes del Enemigo, bajo la responsabilidad de Luis Cabrera Lobato en el marco de las atribuciones asignadas por la Ley Relativa a Propiedades y Negocios del Enemigo del 11 de junio de 1942 y publicada en el Diario Oficial de la Federación dos días después.

El centro de las decisiones políticas las atendía la Junta Intersecretarial Relativa a Propiedades y Negocios del Enemigo, presidida por Eduardo Suárez, secretario de Hacienda y Crédito Público, donde además participaban los responsables de la Secretaría de Relaciones Exteriores, Secretaría de Economía Nacional, Secretaría de Gobernación y la Procuraduría General de la República. 
Es un hecho que la decisión del Ejecutivo mexicano era fundamental por su posición dentro de la estructura del sistema político mexicano de la época; lo anterior era conocido por los políticos y empresarios involucrados, por lo que las comunicaciones a la oficina de la Presidencia e incluso entrevistas con Manuel Ávila Camacho fueron una constante en ese periodo, para solicitarle su intervención directa para resolver las controversias de la posesión de los bienes incautados o la reactivación de las concesiones revocadas.

Un caso emblemático fue el de la empresa Tsuru Mining Co., y los posteriores reclamos para el uso de los derechos de explotación de la Mina Azul ubicada a la altura del kilómetro 151 de la antigua carretera México-Acapulco, Guerrero-, donde se extraía espato de flúor (fluorita), mineral usado en la industria bélica. La concesión de cateo fue otorgada a un particular, Federico Deschamps, desde 1938 y renovada —después de ganar una diligencia judicial ante el intento del Gobierno de recuperarla y reintegrarla a las reservas nacionales- dos semanas antes de finalizar el gobierno de Lázaro Cárdenas (1936-1940) por el subsecretario de Economía, Modesto C. Nollard (Secretaría de Economía Nacional, 1940: 49).

Desde 1940, Deschamps había vendido 11 toneladas de fluorita a la Compañía Internacional de Comercio, propiedad de Kiso Tsuru, pero debido a un problema en la transacción, la compañía de Tsuru embargó a la mina. Después de diversos arreglos mercantiles, se realizó un contrato para ceder los derechos de explotación por un periodo de tres años al ingeniero Carlos Almazán, firmando él mismo en representación de su empresa (Carlos Almazán A. en P.), que controlaría 25\%, y la Tsuru Mining Co., con el restante. Se estableció el compromiso de un pago por adelantado por concepto del volumen de extracción del espato de flúor por seis mil 600 pesos a cuenta de regalías, correspondiente a los primeros tres meses. En el mismo acuerdo mercantil se mencionan los permisos de explotación de la mina "La Fluorita", colindante con la Mina Azul; era Roberto Deschamps que había obtenido la concesión de cateo el 19 de agosto de 1940 (Almazán, 1941: 1-14).

Los vínculos entre Almazán y Tsuru eran muy sólidos en diversos negocios conjuntos en los sectores petrolero y minero. En una presentación de Kiso Tsuru en la Asociación Diplomática de Japón, lo expresaba en los siguientes términos:

Es un personaje relevante del sector petrolero de México y es muy serio. Al principio, fue inspector petrolero en Tampico. Después, trabajó como consejero 
de los campos petroleros en empresas inglesas y estadounidenses [...] Además, participó en la legislación sobre el petróleo como una persona importante del gobierno [...] Desde entonces, fue elegido miembro del Congreso de México varias veces [...] También fue alcalde de la ciudad de Tampico. Fundamos varias empresa [...] las operamos y sacamos ganancias juntos. Somos compañeros inseparables y estamos trabajando con el mismo entusiasmo (Tsuru, 1938: 16 y 17).

En el marco de esas relaciones, la Tsuru Mining Co., inició sus operaciones con un capital de un millón de pesos, de los cuales 300 mil correspondieron a diversos inversionistas mexicanos, 600 mil aportó Tsuru y supuestamente 100 mil correspondían al general Juan Barragán Rodríguez. Después Kiso Tsuru adquiriría las acciones de los mencionados empresarios locales para controlar 90\% de las mismas. Asimismo esa compañía también tuvo derechos de explotación en otra mina llamada "Las Actividades" en Ciudad Guzmán, Jalisco.

La empresa inició sus operaciones pero se enfrentó con un problema sustancial. En julio de 1941 México firmó el acuerdo Douglas-Wiechers para la restricción de recursos estratégicos hacia países fuera del hemisferio occidental, donde Estados Unidos y posteriormente sus aliados eran los únicos compradores autorizados. Esa decisión generaba un panorama inesperado. Por un lado, cancelaría la posibilidad de que el espato de flúor fuera exportado a Japón, ya que el arreglo de la concesión y la fundación de la Tsuru Mining Co., estuvieron orientados a ese motivo. Por otro, las actividades empresariales de Kiso Tsuru en el rubro de comercio, en el ámbito petrolero y el de minerales estaban alineadas a los intereses de Japón, que había contribuido a su financiamiento. Bajo esa perspectiva, era imposible que esa compañía y otras más de ese empresario naturalizado mexicano — que habían sido vigiladas por los servicios de inteligencia estadounidense y después fueron parte de la "lista negra" elaborada por el Gobierno de Estados Unidos el 23 de diciembre de 1941 - pudieran aspirar a vender su producto mineral a Estados Unidos (Proclaimed List, 1941: 11).

El rompimiento de las relaciones diplomáticas, como ya se mencionó, generó inquietud a los diferentes políticos y empresarios que estuvieron involucrados con los negocios patrocinados por las potencias del Eje en México. El mismo día de ese anuncio a la nación por el presidente Manuel Ávila Camacho, el general Juan Barragán Rodríguez le reveló su participación como accionista en empresas japonesas. En un comunicado enviado por el general Federico Montes al Ejecutivo mexicano, lo señalaba así: 
En la misma noche del 7 de diciembre y después de dar lectura el señor presidente de la República a su histórica declaración de rompimiento de relaciones con el Eje, el propio señor general Juan Barragán concretamente expresó que él era socio de la "Turu Mining Company" que pertenecía al enemigo y solicitó del señor presidente que el señor procurador de la República procediera contra la citada "Turu Mining Company" como propiedad del Eje [...] En ese mismo acto el señor presidente de la República habló al señor procurador en presencia del señor Juan Barragán y le instruyó para que de acuerdo con el pedimento del general Barragán, procediera conforme a la Ley, que posteriormente se dictó, relacionada con las propiedades del enemigo (Montes, 1942: 2).

El general Barragán realizó una primera diligencia el 13 de junio con los auditores designados por la Junta de Administración y Vigilancia de los Bienes del Enemigo, como parte del expediente que se abría contra la Compañía Mexicana de Petróleos Laguna S. A., la Compañía Veracruzana S. A., la Compañía Internacional de Comercio S. A., Eduardo Gutiérrez y Compañía; la Mina Azul y Tsuru Mining Company. Para el 4 de agosto de 1942 dirigió un extenso documento al secretario de Hacienda y Crédito Público — como presidente de la Junta Intersecretarial Relativa a la Propiedad y Negocios del Enemigo- donde realizaba una serie de acusaciones contra Kiso Tsuru; las mismas pueden agruparse en básicamente tres: en primer lugar, la creciente influencia económica y política tanto en México como en Japón de ese personaje, manifestándolo del siguiente modo:

Entre los elementos que más daño causan al país dentro del actual estado de guerra, debe señalarse, en primera línea, al súbdito japonés Kiso Turu, quien, para ocultar las actividades que ha venido desarrollando como agente de su gobierno y por conveniencia de sus negocios particulares, tomó carta de naturalización como mexicano. Aunque sin rango diplomático reconocido, tiene más influencia $\mathrm{y}$, por los intereses que maneja, más fuerza que la que han tenido los ministros de su país acreditados en México (Barragán, 1942: 2).

En segundo lugar, la descripción de los flujos de capital provenientes de Japón para el financiamiento de las empresas de Tsuru. De acuerdo con Barragán, existió un derrame de dinero para apoyar a las empresas petroleras (La Laguna y La Veracruzana) y mineras (La Azul) donde apunta que el empresario de origen japonés hacía uso de los recursos para el desarrollo de las mismas pero también no sólo canalizándolos a través de sus negocios personales sino también desviando recursos para el beneficio de los mismos. Apunta el hecho de 
que después del rompimiento de las relaciones diplomáticas bilaterales, unos japoneses internaron al país desde Estados Unidos la cantidad de dos millones de dólares, a los que tuvo acceso Tsuru por medio de la legación de Suecia:

\begin{abstract}
Al recibirlo éste, guardó una parte en una caja que tiene en la casa de su banquero, otra parte en la de otra persona, la cual sacó hace ya varias semanas, ignorándose a dónde la haya ocultado, y del resto estuvo haciendo fuertes compras de mercancías para la Int. de Comercio (alrededor de 2'000,000 pesos) y completó la instalación y equipo de transporte de la "Mina Azul" y los gastos de enero a la fecha de este negocio, empleando en total unos 600,000.00 pesos (Barragán, 1921: 4 y 5).
\end{abstract}

Más allá de la credibilidad de sus argumentos, ya que parecía extraño que el ministro sueco en México le hubiera entregado a un particular esa cantidad, además de las dudas que pueden derivarse sobre la posibilidad de ingresar esa fuerte cantidad de dinero cuando las autoridades mexicanas y sobre todo los servicios de inteligencia de Estados Unidos habían dispuesto una vigilancia tanto en la residencia del ministro Yoshiaki Miura -el último representante diplomático de Japón en México - como en la casa donde se ubicaba la Legación japonesa. Lo importante es que el general Barragán deseaba que las autoridades pudieran decomisar esos recursos financieros, que al parecer no estaban registrados en sus cuentas bancarias y de sus empresas.

Como el dejar esos fondos en sus manos que, con ninguna buena intención ha ocultado, aparte de la falta que implica su ocultación, sería sumamente peligroso; se hace necesaria la inmediata intervención de las autoridades, tanto para que se recoja y depositen dichos fondos, como lo ordena la Ley relativa, como para impedir que Tsuru y sus ayudantes japoneses hagan mal uso, como lo han venido haciendo, de cuanto dinero queda en su poder (Barragán, 1942: 5).

En tercer lugar, las operaciones de la Mina Azul, donde el general Barragán señala que cuando se inició el proceso de restricción de exportaciones de materiales estratégicos y la aparición de la "Tsuru Mining Co." en la lista negra, Kiso Tsuru transfirió el contrato de arrendamiento de la mina a Cipriano Rodríguez Pastor, de origen español, usándolo como prestanombres para mantener el control de la empresa. En el documento entregado a las autoridades mexicanas lo refrenda en los siguientes términos: 
Para fin de tener para él solo la totalidad de dicho negocio, del que esperaba sacar grandes utilidades, desposeyó a la "Turu" de los derechos que presentaba como asociada, dejándola solamente como acreedora de Rodríguez Pastor, por el capital invertido en la mina, parte del cual había puesto previamente a nombre de dicho individuo. Esta maniobra de Turu dio lugar a un juicio de carácter penal que lo promovió el suscrito, por constituir un fraude para los intereses de la "Turu" de la cual el propio suscrito es accionista (Barragán, 1942: 8).

De acuerdo con Barragán, al iniciarse la intervención de la empresa, Cipriano Rodríguez Pastor — quien había informado a la embajada de Estados Unidos que Tsuru se había desligado ya de la misma - se observó que era insolvente y que no podía comprobar que las inversiones fueron hechas por él mismo; después declaró para justificar su liquidez financiera, que tenía una asociación desde mes de enero de 1942 con Jiro Iwamoto (empleado de la Compañía Internacional de Comercio), de quien recibió la cantidad de 1'038,000 pesos para el negocio (Barragán, 1942: 9 y 10).

De lo anterior puede inferirse que dentro de esa red de sesión de derechos de propiedad de las empresas con la complicidad de personas de confianza (usando amigos leales y empleados de la Compañía Internacional de Comercio) como prestanombres, el doctor Tsuru trató de mantener a través del uso de todos los recursos mercantiles, administrativos y legales el control indirecto de la operación de sus negocios. El mismo Barragán calificaba sus actividades de la manera siguiente:

En lo que toca a actividades que bien pueden calificarse de subversivas, Turu, como japonés y como agente de su Gobierno y además, por su espíritu antimexicano que, en lo que le conviene encubre con una fingida adhesión a México, es no solamente "un enemigo", sino "el enemigo número uno", precisamente por el gran poder que le da el dinero con el que cuenta (Barragán, 1942: 10).

El general Barragán procedió al reclamo de los derechos de explotación de la Mina Azul usando dos vías. Por una parte, la interposición de una demanda por fraude contra Kiso Tsuru, cuyo proceso jurídico se elevó al Tribunal General de la Nación para la valoración de la viabilidad del recurso de amparo obtenido por el empresario naturalizado mexicano. Por otra, el endoso de su supuesta participación en la Tsuru Mining Co., al general Federico Montes como una forma de tener otro frente de presión para el presidente Manuel Ávila Camacho. 
En relación con la querella jurídica, el general Barragán presentó ante el Tribunal Superior del Distrito Federal una acusación de fraude contra Tsuru, donde el juez séptimo de la Tercera Corte Penal dictaminó contra el acusado en una sentencia fechada el 2 de agosto de 1942 donde se declaraba el auto de formal prisión. El representante legal de Tsuru, Carlos Franco Sodi, presentó un recurso de amparo y se analizó su viabilidad en la Primera Sala de la Suprema Corte de Justicia de la Nación. El ministro Fernando de la Fuente apuntó en su ponencia que era de revocarse el fallo del juez que había otorgado el amparo. En la lectura de un documento anexo presentado por los defensores legales de Tsuru, señalaba enfáticamente que el general Barragán "no puso un solo centavo y que todo el capital de un millón de pesos fue aportado por el quejoso, quien se asoció con otros mexicanos para la explotación del mineral mencionado" (Secretaría de Gobernación, 1942: 2). Asimismo se apuntaba que políticos mexicanos habían estado involucrados en sus negocios. Lo anterior mereció la indignación del ministro Teófilo Olea y Leyva que, de acuerdo con las crónicas de los periódicos apuntó:

\begin{abstract}
[...] que la honorabilidad del general Barragán estaba, en su sentir, por encima de las sospechas de Tsuru, así como la de los funcionarios que el reo mencionaba maliciosamente en sus escritos y a quienes no guarda ningún respeto ni consideración, olvidándose de su carácter de enjuiciado, de su condición de extranjero y súbdito de un país con el que México está en guerra. Francamente - dijo - yo no concedo derecho a un extranjero para que se trate en esa forma descomedida a funcionarios de mi país, ni aun en el caso de que se concediera que sus apreciaciones tuvieran algún fundamento, del que carecen (Secretaría de Gobernación, 1942: 2).
\end{abstract}

A pesar de la irritación por la mención de los políticos mexicanos, era un hecho que estaba plenamente documentado por los servicios de inteligencia y que la misma Embajada de Estados Unidos había advertido al Gobierno mexicano. La estrategia de Tsuru fue efectiva - a pesar de que corrieron los alegatos de ambas partes dentro de la justicia mexicana, donde se negó el recurso de amparo por parte de la Suprema Corte de Justicia-, no se finalizó con el hecho de que hubiera cumplido la sentencia posiblemente al llegar a un arreglo privado con la parte afectada.

Además, el general Barragán, como se apuntó, realizó un acuerdo con el general Federico Montes para que fuera copartícipe de $10 \%$ de las acciones que aseguraba tener en la Tsuru Mining Co. De acuerdo con su escrito, el general 
Barragán, como accionista, había recibido las garantías de que se le permitirían los derechos de explotación de la mina. El general Montes lo apunta así:

\begin{abstract}
El señor Lic. Eduardo Suárez, presidente de la Junta Intersecretarial, hizo saber al general Barragán que su participación en la "Turu Mining Company" quedaría asegurada y con este motivo el general Barragán elevó dos escritos a la Junta Intersecretarial para que se le reconocieran sus derechos, pero como el señor. Lic. Suárez ha estado ausente, nada se ha resuelto no obstante que el art. $2^{\mathrm{a}}$ del reglamento de dicha Junta previene que los derechos de los accionistas mexicanos, que nada tienen que ver con los enemigos de la nación, se les reconozcan y respeten (Montes, 1942: 2).
\end{abstract}

La Junta de Administración y Vigilancia de los Bienes del Enemigo identificó — de acuerdo con la legislación respectiva - a la mina "La Azul" como un negocio vinculado a los intereses de las potencias del Eje, en particular de Japón, por lo cual procedió a su confiscación de acuerdo con el decreto del 9 de septiembre de 1942; 20 días después la Junta de Administración y Vigilancia publicó las bases del concurso para la obtención de los derechos de explotación de la mina "La Azul". Mismo que se celebró el 29 de octubre de 1942, con la participación de las siguientes empresas: Comercio General S. A.; Metales Mexicanos S. A; señor John C. McDonald; señor John M. Heyman (ex director técnico de la mina) y senador y general Nabor A. Ojeda Caballero. Muchos interesados se presentaron ejerciendo todo tipo de influencias para obtener el permiso tan codiciado, ya que la exportación del espato de flúor estaba garantizada por la demanda estadounidense de ese mineral estratégico. Ese negocio altamente lucrativo, es de suponer, era el motivo de la insistencia del general Barragán y Montes para ser los beneficiarios, donde incluso apelaban para ello su amistad con el representante del Poder Ejecutivo mexicano.

El general Federico Montes solicita y suplica al señor presidente que, por consideraciones de orden moral, de carácter legal o en todo caso de jefe, compañero y amigo, se le prefiera en unión del general Barragán para explorar los yacimientos de la mina "La Azul", ya sea que se consideren pertenecientes al concesionario señor Dechamps [sic] o formando parte de las Reservas Nacionales (Montes, 1942: 3 y 4).

Es interesante la mención de Federico Deschamps, ya que al parecer podría deducirse algún tipo de acuerdo con los generales para continuar la operación de la empresa. Sin embargo, no hay evidencias sobre esa vinculación. 
No existen argumentos contundentes para afirmar que Deschamps buscó obtener para sí los beneficios que le acreditaba como concesionario original de la mina ya que estuvo reclamando los mismos en las instancias jurídicas hasta mediados de la década de los cincuenta, o si Tsuru pudiera haber tenido en él influencia para seguir sirviendo de prestanombres para los intereses de los japoneses. Es interesante también notar la pérdida del rastro de los reclamos del general Barragán y Montes, pero emerge, al mismo tiempo, otro personaje como el general Nabor A. Ojeda Caballero, senador por el estado de Guerrero, donde no existen todavía evidencias suficientes de un nexo con ellos, aunque es posible, por ser compañeros de armas y actores políticos de importancia en esa época.

De manera independiente, de los supuestos hipotéticos fue contundente la decisión del presidente Ávila Camacho para suspender el concurso usando la vía de reintegrar la propiedad de la mina "La Azul" a la Comisión de Fomento Minero con fecha 18 de diciembre de 1942 como resultado del término de la concesión de cateo expirada dos días antes de la referida fecha (Secretaría de Economía Nacional, 1943a: 4). Asimismo establece el acuerdo para revocar la disposición de la ocupación de la mina "La Azul" y se establece que la Junta de Administración y Vigilancia mantendría bajo su control el material extraído, maquinaria e inversiones (Secretaría de Hacienda y Crédito Público, 1943: 8 y 9).

La búsqueda de la concesión y de los derechos de explotación prosiguió. El general Ojeda buscó de manera insistente la intervención del Ejecutivo mexicano para evitar la restitución de los títulos de concesión a Deschamps, que supuestamente ante la cancelación de los derechos de explotación de la Tsuru Mining Co., había establecido un acuerdo con otro inversionista llamado John McDonald por un periodo de 20 años. El senador Ojeda Caballero apuntaba:

La negligencia usada en este caso, ha dado origen a que los agentes de los japoneses, escudados en el señor Dechamps se estén valiendo de argucias y artimañas, tales como la interposición de amparos improcedentes, con los que sólo consiguen el que indefinidamente continúe paralizada la mina, con los consiguientes perjuicios para la economía nacional, de mi estado, de los trabajadores y de mis intereses, los que día a día se lesionan por los compromisos que ya tengo contraídos (Ojeda, 1943: 1).

Deschamps interpuso una serie de amparos que generaron que el plan de Ojeda para operar la mina bajo un supuesto acuerdo con el Ejecutivo no se 
llevara a cabo inmediatamente. El senador afirmaba que había constituido una empresa con un capital de 500 mil pesos para iniciar los trabajos de explotación, la cual se estableció con el nombre Compañía Minera Nacional de Taxco y cuyo socio fue Vladimir Geisman. El 7 de diciembre, el lote de la mina "La Azul" fue desincorporado de las reservas mineras nacionales (Secretaría de Economía Nacional, 1943: 6), la concesión fue establecida por tres años y el 18 de enero de 1946, tiempo después de finalizar la Segunda Guerra Mundial, se suspendieran sus trabajos debido a la ausencia de la "costeabilidad", pues el material extraído era catalogado de carácter bélico.

La administración de los bienes de las personas físicas y morales de los ciudadanos de las potencias del Eje en México, se convirtió en un tema central dentro de la política mexicana, donde el tráfico de influencia, el reclamo del pago de favores políticos y gran estela de corrupción facilitaban las acciones para el mantenimiento de las mismas a través de prestanombres o del interés de ellos para apropiarse de las empresas. Las contiendas de los grupos de poder buscaban en el Ejecutivo que fuera el gran árbitro que inclinara la balanza a favor de los interesados. Al mismo tiempo, en los tribunales se desahogaban innumerables casos para preservar los derechos y concesiones otorgadas por el Estado mexicano. Quizá las ofensivas más intensas se dieron al interior del escenario político de México, que en el anfiteatro externo de hostilidades de la Segunda Guerra Mundial.

\section{Reflexión final}

El Gobierno mexicano tardó 166 días para tomar una decisión que se esmeró en aplazar desde el rompimiento de las relaciones diplomáticas con Japón y las potencias del Eje en diciembre de 1941. Es un hecho que desde el ataque japonés a Pearl Harbor, el ambiente internacional se modificó ante el ya esperado conflicto entre Tokio y Washington. Para México, la inicial declaración de neutralidad ante el conflicto en el escenario europeo se observaba compleja de sostener. El apego a los acuerdos panamericanos de seguridad estaba en consonancia con el perfil legalista y de los principios de la política exterior mexicana en ese momento de crisis.

El tránsito desde los últimos meses del gobierno cardenista, de una política comercial más apegada a Estados Unidos - donde las medidas restrictivas del comercio se agudizaron-, encontró eco ya con la administración de Manuel Ávila Camacho, donde de manera clara se adhiere a las acciones del embargo 
económico contra Japón. En el terreno internacional, México también se alejaba de las acciones japonesas para la construcción de la Gran Esfera de Coprosperidad Económica del Este Asiático y de su avance en China. En el plano bilateral, sólo quedaban pronunciamientos protocolarios y de remembranza de la amistad entre los dos países.

Es un terreno fértil la documentación sobre las actividades de espionaje de Japón en México y en América Latina. Los servicios de inteligencia fueron muy sensitivos de monitorearlos y documentarlos; con independencia de la histeria y paranoia de la "amenaza japonesa" que alimentaron los innumerables reportes, es un hecho que el personal diplomático, los representantes de los zaibatsu y las redes con algunos sectores de las comunidades japonesas consideraban una necesidad establecer acciones para contener la política de acorralamiento que había adoptado Washington y legitimaban así la "acción justa” para lograr un nuevo espacio vital para el emergente Imperio japonés. En este sentido se podría recurrir a cualquier medio para lograr los fines deseados.

Como se observó, México asumió una actitud de acuerdo con sus intereses. Lo anterior se observó claramente con el rompimiento de las relaciones diplomáticas con las potencias del Eje y la aplazada declaración del estado de guerra. México se resistió al anuncio de una proclamación de guerra de manera directa, se apegó de manera hábil al derecho internacional para mostrar su compromiso con Estados Unidos, pero al mismo tiempo eligió una acción defensiva frente a las agresiones "totalitarias" que derivaron del bombardeo del "Faja de Oro" y "Potrero del Llano" y la pérdida de vidas humanas.

Mientras las notas diplomáticas de México eran ignoradas por Alemania, Italia y Japón en el marco de la declaración del estado de guerra, un nuevo campo de batalla se libraba al interior del sistema político mexicano, en el que se involucraba el manejo de los bienes financieros y materiales, concesiones y derechos de explotación de los recursos de la nación que tenían particulares o empresas identificadas como pertenecientes a ciudadanos — muchos de ellos ya naturalizados mexicanos-de las potencias del Eje. Como se pudo apreciar en el caso de la mina "La Azul", significó el uso de todos los recursos posibles de tipo personal y legal hasta presiones políticas para, en una primera instancia, deslindarse de los vínculos que los empresarios y políticos mexicanos habían cultivado con intereses japoneses, alemanes o italianos, pero después ellos mismos vieron un negocio garantizado decidiendo tomar el control de sus empresas, derechos y concesiones otorgadas. La gran mayoría de las personas físicas y morales afectadas no pudieron recuperar en su totalidad su 
patrimonio material y económico labrado durante su ya larga residencia en el país o del trabajo de sus descendientes nacidos en el territorio nacional. Otros muy pocos - como el doctor Kiso Tsuru - lograron restablecer sus negocios durante el periodo de la posguerra.

\section{Referencias bibliográficas}

Libros

Hernández Galindo, Sergio (2011), La guerra contra los japoneses en México durante la Segunda Guerra Mundial. Kiso Tsuru y Masao Imuro, migrantes vigilados, Ítaca.

Artículos de periódicos

El Universal (1941a), "Desde ayer cortó México sus relaciones con Tokio", 9 de diciembre, p. 1.

_- (1941b), “México ante el conflicto”, 11 de diciembre, p. 1.

- - (1941c), "México rompió sus relaciones con el Tercer Reich y con Italia", El Universal, 12 de diciembre, p. 1.

- - (1941d), "Nuestra historia está limpia de toda mancha internacional", 10 de diciembre, p. 3.

- - (1942), "Lacónica declaración hecha por la Secretaría de Relaciones", 22 de mayo, p. 1.

Excélsior (1942a), "Decisiones que exija el honor", 15 de mayo, p. 1.

- - (1942b), Votó la declaración de la guerra y la suspensión de garantías individuales", Excélsior, primera sección, 30 de mayo, p. 1.

Flores M., Alfonso (1941), "La guerra, Ávila Camacho y su mensaje”, El Universal, 12 de diciembre, p. 3.

Secretaría de Economía Nacional (1943a), "Acuerdo que adiciona la lista de personas comprendidas en la Ley relativa a Propiedades y Negocios del Enemigo", Diario Oficial de la Federación, 8 de enero.

- - (1943b), "Declaratoria que desincorpora del patrimonio de la Comisión de Fomento Minero los derechos para la explotación del lote La Azul, en Taxco de Alarcón, Gro.", Diario Oficial de la Federación, 8 de diciembre.

Secretaría de Gobernación (1943), "Acuerdo que revoca en su tarifa relativa el que ordenó la ocupación de la mina 'La Azul', en Taxco, Gro.", Diario Oficial de la Federación, 27 de marzo. 
Cibergrafía

Almazán, Carlos (1941), Contrato mercantil con Federico y Roberto Deschamps, acta 3677, vol. trigésimo séptimo. Japan Center for Historical Records, A-1763. Recuperado de: http://www.jacar..go.jp

Ávila Camacho, Manuel (1942), Discurso del presidente Manuel Ávila Camacho informando que México declara la guerra a las potencias del Eje, 28 de mayo. Recuperado de: http://www.inehrm.gob.mx/pdf/documento_segunda\%20guerra2.pdf

Secretaría de Economía Nacional (1940), Título de concesión, 15 de noviembre. México: Japan Center for Historical Records, A-1763. Recuperado de: http://www.jacar..go.jp

Tsuru, Kiso (1938), メキシコにおける邦人石油利権について(La concesión del petróleo de los japoneses en México), 日本外交協会 (Asociación Diplomática de Japón) 昭和13年6月 (junio de 1938), pp. 16-17, Japan Center for Historical Records, A-0632. Recuperado de: http://www.jacar..go.jp

Documentos

Autor no especificado (1941), "The Proclaimed List of Certain Blocked Nationals”, Supplement, núm. 6, diciembre 23.

Barragán Rodríguez, Juan (1942), “Carta dirigida a Enrique Suárez, secretario de Hacienda y Crédito Público y presidente de la Junta Intersecretarial Relativa a Propiedad y Negocios del Enemigo", fechada el 4 de agosto de 1942, México: Archivo General de la Nación, Expediente 550/35-11, $\mathrm{M} / \mathrm{C}$ C-827.

Montes, Federico (1942), “Memorándum que presenta el general Federico Montes a la consideración del señor presidente de la República sobre el asunto de 'La Mina Azul'", fechado el 6 de noviembre de 1942, México: Archivo General de la Nación, Expediente 550/35-11, M/c C-827.

Ojeda, A. Nabor (1943), "Carta dirigida al presidente Manuel Ávila Camacho", fechada el 29 de enero de 1943, México: Archivo General de la Nación, Expediente 550/35-11, M/c C-827.

Secretaría de Gobernación-Departamento de Investigaciones Políticas y Sociales (1942), "Kiso Tsuru, su movilización", agosto, México: Archivo General de la Nación 2-1/362.4(52)/1339, documento núm. 2 sobre una noticia intitulada "Incidente escandaloso en la Suprema Corte", El Universal, segunda sección, 16 de marzo de 1943, p. 14. 